\title{
Development of a Human Estrogen Receptor Dimerization Assay for the Estrogenic Endocrine-Disrupting Chemicals Using Bioluminescence Resonance Energy Transfer
}

\author{
Hye Mi Kim ${ }^{1,+}$, Hyeyeong Seo ${ }^{2,+}$, Yooheon Park ${ }^{3}$, Hee-Seok Lee ${ }^{4}$, Seok-Hee Lee ${ }^{3, *(D)}$ and Kwang Suk Ko ${ }^{1, *(D)}$ \\ 1 Department of Nutritional Science and Food Management, Ewha Womans University, Seoul 03760, Korea; \\ gpaldlt@gmail.com \\ 2 Department of Integrated Biomedical and Life Science, Korea University, Seoul 02841, Korea; \\ hishyung20@gmail.com \\ 3 Department of Food Science and Biotechnology, Dongguk University, Goyang 10326, Korea; \\ ypark@dongguk.edu \\ 4 Department of Food Science and Technology, Chung-Ang University, Anseong 17546, Korea; \\ hslee0515@cau.ac.kr \\ * Correspondence: seokhee@dongguk.edu (S.-H.L.); kko@ewha.ac.kr (K.S.K.); Tel.: +82-31-961-5187 (S.-H.L.); \\ +82-2-3277-6859 (K.S.K.) \\ + Authors contributed equally.
}

check for updates

Citation: Kim, H.M.; Seo, H.; Park, Y.; Lee, H.-S.; Lee, S.-H.; Ko, K.S. Development of a Human Estrogen Receptor Dimerization Assay for the Estrogenic Endocrine-Disrupting Chemicals Using Bioluminescence Resonance Energy Transfer. Int. J. Environ. Res. Public Health 2021, 18, 8875. https://doi.org/10.3390/ ijerph18168875

Academic Editor: Paul B. Tchounwou

Received: 14 July 2021

Accepted: 19 August 2021

Published: 23 August 2021

Publisher's Note: MDPI stays neutral with regard to jurisdictional claims in published maps and institutional affiliations.

Copyright: (c) 2021 by the authors. Licensee MDPI, Basel, Switzerland. This article is an open access article distributed under the terms and conditions of the Creative Commons Attribution (CC BY) license (https:// creativecommons.org/licenses/by/ $4.0 /)$.

\begin{abstract}
Endocrine-disrupting chemicals (EDCs) are found in food and various other substances, including pesticides and plastics. EDCs are easily absorbed into the body and have the ability to mimic or block hormone function. The radioligand binding assay based on the estrogen receptors binding affinity is widely used to detect estrogenic EDCs but is limited to radioactive substances and requires specific conditions. As an alternative, we developed a human cell-based dimerization assay for detecting EDC-mediated ER-alpha $(E R \alpha)$ dimerization using bioluminescence resonance energy transfer (BRET). The resultant novel BRET-based on the ER $\alpha$ dimerization assay was used to identify the binding affinity of $17 \beta$-estradiol (E2), $17 \alpha$-estradiol, corticosterone, diethylhexyl phthalate, bisphenol A, and 4-nonylphenol with ER $\alpha$ by measuring the corresponding BRET signals. Consequently, the BRET signals from five chemicals except corticosterone showed a dose-dependent sigmoidal curve for $\mathrm{ER} \alpha$, and these chemicals were suggested as positive chemicals for $\mathrm{ER} \alpha$. In contrast, corticosterone, which induced a BRET signal comparable to that of the vehicle control, was suggested as a negative chemical for ER $\alpha$. Therefore, these results were consistent with the results of the existing binding assay for ER $\alpha$ and suggested that a novel BRET system can provide information about EDCs-mediated dimerization to ER $\alpha$.
\end{abstract}

Keywords: estrogenic endocrine-disrupting chemical; estrogen receptor; bioluminescence resonance energy transfer; risk assessment

\section{Introduction}

Endocrine-disrupting chemicals (EDCs) interfere with the functions of the endocrine system by mimicking or blocking hormone function in humans and animals. Absorption of EDCs in vivo can inhibit or stimulate the production of hormones and their metabolisms to increase the risk of diseases, such as reproductive disorders and hormone-related cancer [1,2]. A considerable number of EDCs are widely found in everyday products, such as industrial solvents/byproducts, agricultural pesticides, plastics, and other manufactured products, and also include natural chemicals, such as phytoestrogen $[3,4]$. These contaminants may enter the food chain by direct contact with food components [5,6]. For instance, phenolic EDCs from industrial sewage plant flow in the aquatic environment and bisphenol A, another kind of EDC, are contained in plastics used for food packing materials or beverage containers. Exposure and accumulation of bisphenol A in the body can cause 
changes in body weight and fat mass or increasing diabetes or cardiovascular disease [7-9]. Among EDCs found everywhere in human life, including foods and food ingredients, are the chemicals that disrupt the physiological functions of estrogen, which are called estrogenic EDCs [10]. These estrogenic EDCs were associated with behavioral changes, reproductive disorders, and cancer development in both vertebrates and invertebrates by mimicking estrogenic functions [11]. Therefore, to detect or evaluate estrogenic EDCs that interfere with normal estrogen function is necessary because estrogenic EDCs can be released into the environment and are subsequently exposed to the human body [12].

Various methods exist to evaluate estrogenic EDCs. These assays are based on the molecular and cellular mechanisms of estrogen action, such as reporter gene assay, yeast two-hybrid assay, transcription assay, protein assay, cell assay, animal tests, and ligandbinding assay [13]. Among the in vitro methods of detecting EDCs, the performancebased test guideline for human recombinant estrogen receptor-alpha $(E R \alpha)$ using binding assay (OECD TG 493) recommended by the Organisation for Economic Co-operation and Development (OECD) is the most popular method for the initial screening step and is regarded as the most convenient approach [14]. This radioligand binding assay [15] measures the ability of a radiolabeled ligand $\left(\left[{ }^{3} \mathrm{H}\right] 17 \beta\right.$-estradiol) to bind with ER-alpha $(\mathrm{ER} \alpha)$ when in the presence of competitor chemicals. The main advantages of this method are its sensitivity and specificity. However, its disadvantages include relatively long read times, high cost, health risk, requirement for specific laboratory licenses, and difficulty of radioactive waste disposal [16]. For these reasons, the development of new screening methods is necessary for detecting estrogenic EDCs.

Resonance energy transfer is an electrodynamic phenomenon in the relationship between the two molecules, donor (the energy-giving molecule) and acceptor (the energyreceiving molecule), when the distance between the two molecules approaches 1-10 nm and is applied as a powerful system to investigate protein-protein interactions and ligandreceptor interactions [17]. Two main types of RET methods are used: fluorescence resonance energy transfer (FRET) and bioluminescence resonance energy transfer (BRET). In FRET systems, both the donor and the acceptor use fluorophores. A cyan fluorescence protein and the yellow fluorescence protein are the most used FRET pair [18]. The main disadvantage of FRET is the low signal-to-noise ratio caused by the spectral crosstalk between the two fluorophores as well as photobleaching of the acceptor [19]. The BRET method is based on the same principle but replaces the donor with a bioluminescent protein [20]. The bioluminescent donor used in BRET by catalytic oxidation of the substrate transfers energy to the acceptor, which, in turn, emits a fluorescent signal from an acceptor [21]. In comparison to FRET, BRET is much easier to quantify and can obtain enough signal-to-noise at the concentration of a donor forty times lower [22].

The objective of this study was to analyze the binding affinity of EDCs using the BRET technique. To this end, we developed a human cell-based dimerization assay that provides information about EDCs binding to ER, as well as the background for developing an in vitro dimerization assay.

\section{Materials and Methods}

\subsection{Chemicals}

Chemicals $17 \beta$-Estradiol (E2), 17 $\alpha$-estradiol, corticosterone, diethylhexyl phthalate, bisphenol A, and 4-nonylphenol were obtained from Wako Chemicals (Richmond, VA, USA), Sigma-Aldrich (St. Louis, MO, USA), and Tokyo Chemical Industry (TCI, Tokyo, Japan). All chemicals were dissolved in DMSO.

\subsection{Cell Culture}

The human embryonic kidney (HEK293) cell line was obtained from the American Type Culture Collection (ATCC, Manassas, VA, USA). HEK293 cells were routinely maintained in minimum essential medium (MEM; Thermo Fisher Scientific, Waltham, MA, USA) supplemented with $10 \%$ fetal bovine serum (FBS; Atlas biologicals, Fort Collins, CO, USA) 
and $50 \mathrm{U} / \mathrm{mL}$ penicillin-streptomycin (Gibco, Thermo Fisher Scientific) at $37^{\circ} \mathrm{C}$ in a $5 \%$ $\mathrm{CO}_{2}$ humidified incubator. Before the BRET-based dimerization assays, the cells medium was changed to Opti-MEM ${ }^{\mathrm{TM}}$ I Reduced Serum Medium, no phenol red (Opti-MEM; Thermo Fisher Scientific) supplemented with $4 \%$ charcoal-stripped FBS (Access Biologicals, Vista, CA, USA), $25 \mu \mathrm{g} / \mathrm{mL}$ Hygromycin B Gold (InvivoGen, San Diego, CA, USA), and $400 \mu \mathrm{g} / \mathrm{mL}$ G418 (InvivoGen), because using charcoal-stripped FBS removes the sex steroids from FBS.

\subsection{Construction and Preparation of Vector Containing the Estrogen Receptor-Alpha}

NanoLuc luciferase (Nluc) fusion protein construction, expression, and purification were performed using the pFN31A Nluc CMV-Hygro Flexi ${ }^{\circledR}$ Vector (6308 bp) for the amino-terminal and the pFC32A Nluc CMV-Hygro Flexi ${ }^{\circledR}$ Vector (6299 bp) for the carboxylterminal (Promega, Madison, WI, USA). The HaloTag (HT) fusion protein was constructed using the pFN28A HaloTag ${ }^{\circledR}$ CMV-neo Flexi ${ }^{\circledR}$ Vector $(6524 \mathrm{bp})$ for the amino-terminal and the pFC27A HaloTag ${ }^{\circledR}$ CMV-neo Flexi ${ }^{\circledR}$ Vector (6524 bp) for the carboxyl-terminal, respectively (Promega). ESR1-HaloTag ${ }^{\circledR}$ human ORF in pFN21A (human ER $\alpha$ clone) was purchased from Promega. It was obtained from the human ER $\alpha$ DNA sequence using the restriction-enzyme pair Sgfl/Pmel. The digested DNA fragment was inserted into the Nluc and the HT vectors, respectively. The construction of the fusion vectors was confirmed by agarose gel electrophoresis.

\subsection{Transient Transfection to HEK293 Cells}

The prepared plasmid DNA was transformed into Escherichia coli DH5a (Invitrogen, CA, USA) for amplification. Briefly, $2 \mu \mathrm{L}$ of plasmid DNA was added to $40 \mu \mathrm{L}$ of $E$. coli and allowed to incubate on ice for $40 \mathrm{~min}$. The transformed cells were then spread on a Luria-Bertani (LB) agar plate supplemented with $50 \mu \mathrm{g} / \mathrm{mL}$ ampicillin. The plasmid was isolated from E. coli using QIAprep Spin miniprep kit (Qiagen, Hilden, Germany) according to the manufacture's recommendations. HEK293 cells were maintained, as described in Section 2.2, and the transfection of the ER $\alpha$ fusion vectors with Nluc and HT was performed in MEM supplemented with $10 \% \mathrm{FBS}$ and $50 \mathrm{U} / \mathrm{mL}$ penicillin-streptomycin. The cells were then seeded in a 6-well plate at a density of $5 \times 10^{5}$; cells per well. The plate with the seeded cells was incubated at $37{ }^{\circ} \mathrm{C}$ in a $5 \% \mathrm{CO}_{2}$ incubator. After $24 \mathrm{~h}$, transient transfection was performed with Lipofectamine ${ }^{\mathrm{TM}} 3000$ Transfection Reagent (Invitrogen) according to the manufacturer's recommended protocol. To identify the optimal donor-acceptor combination and ratio, lipofectamine 3000 was transiently cotransfect HEK 293 cells with four donor-acceptor combinations (Nluc-ER $\alpha+$ HT- ER $\alpha$, Nluc-ER $\alpha+E R \alpha-H T, E R \alpha-N l u c+H T-E R \alpha$, and ER $\alpha$-Nluc + ER $\alpha-H T)$ at four different donor-acceptor ratios (625 ng:625 ng, $62.5 \mathrm{ng}: 625 \mathrm{ng}$, $6.25 \mathrm{ng}: 625 \mathrm{ng}$, 0.625 ng:625 ng). These transient transfections were performed according to the technical manual of the NanoBRET ${ }^{\mathrm{TM}}$ Protein:Protein Interaction System (Promega).

\subsection{Bioluminescence Resonance Energy Transfer-Based Dimerization Assay}

The BRET signal was measured using a NanoBRET ${ }^{\mathrm{TM}}$ Nano-Glo ${ }^{\circledR}$ Detection System (Promega) according to the manufacturer's guidelines. The medium was removed from the culture dish of transfected cells and washed once with Dulbecco's phosphate-buffered saline (Gibco). Then, $500 \mu \mathrm{L}$ of $0.25 \%$ trypsin-EDTA (Gibco) was added to separate the cells from the bottom of the culture dish. An equal volume of assay medium was added to OptiMEM containing 4\% charcoal-stripped FBS, $25 \mu \mathrm{g} / \mathrm{mL}$ Hygromycin B Gold, and $400 \mu \mathrm{g} / \mathrm{mL}$ G418 after centrifugation at $12,000 \times g$ for $5 \mathrm{~min}$. The cells were seeded in 96 well-plates $\left(2 \times 10^{5}\right.$ cells $/ \mathrm{mL}$ ), and $1 \mu \mathrm{L} / \mathrm{mL}$ HaloTag ${ }^{\circledR}$ NanoBRET ${ }^{\mathrm{TM}} 618$ (Promega) as a ligand $(+)$ or $1 \mu \mathrm{L} / \mathrm{mL}$ DMSO as a ligand (-) was added, followed by incubation at $37^{\circ} \mathrm{C}$ for $60 \mathrm{~min}$ in $5 \% \mathrm{CO}_{2}$ incubator.

Afterward, the cells were treated with E2 (final concentration of cells, $10^{-7}-10^{-12}$ $\mathrm{M})$ as a reference control, $17 \alpha$-estradiol (final concentration of cells, $10^{-6}-10^{-11} \mathrm{M}$ ) as a 
positive control, corticosterone (final concentration of cells, $10^{-6}-10^{-11} \mathrm{M}$ ) as a negative control, and DMSO (final concentration of cells, $0.1 \%$ ) as the vehicle control (VC). The cells were then incubated for $24 \mathrm{~h}$. The NanoBRET ${ }^{\mathrm{TM}}$ Nano-Glo ${ }^{\circledR}$ Substrate (Promega) was diluted 100-fold with Opti-MEM and was added to each well after $24 \mathrm{~h}$. Donor emission $(460 \mathrm{~nm})$ and acceptor emission $(618 \mathrm{~nm})$ signals were measured within 10 min using the GloMax ${ }^{\circledR}$ Discover System (Promega).

\subsection{Data Acquisition and Analyses}

The BRET signal was measured using the GloMax ${ }^{\circledR}$ Discover System (Promega). The result was calculated as follows in Equation (1):

$$
\text { Raw BRET unit }=\frac{\text { Acceptor emission value }(618 \mathrm{~nm})}{\text { Donor emission value }(460 \mathrm{~nm})}
$$

The signal was corrected for the background of donor, as shown in Equation (2):

Corrected BRET unit = Raw BRET unit in the presence of HaloTag ligand Mean of raw BRET unit in the absence of HaloTag ligand

Fold induction was calculated as a measured of change between each of the chemical treatment groups and the VC in Equation (3).

$$
\text { Fold Induction }=\frac{\text { Corrected BRET unit of the chemical treatment group }}{\text { Mean corrected BRET unit of VC }}
$$

The fold induction corresponding to the reference control $\left(\mathrm{E} 2,10^{-9} \mathrm{M}\right)$ value needed to be at least 2.5 -fold higher than the mean VC $(0.1 \%$ DMSO) $(=1)$ for vector combination ratio and position test in BRET assay. The mean difference among experimental E2 or chemical treatment groups was analyzed for statistical significance difference using Sigmaplot ver. 14.0 (Systat Software Inc., San Jose, CA, USA) by one-way analysis of variance (ANOVA), post-hoc Tukey's test, and Duncan's test. Statistical significance ( $p$-value) was verified within 5\%. All data represent the average value from three wells in each experiment and are expressed as mean \pm standard deviation for three independent experiments on different days.

\section{Results}

3.1. Design and Construction of NanoLuc Luciferase and HaloTag Fused with Estrogen Receptor-Alpha

Vectors encoding all possible combinations of N- (Nluc-ER $\alpha, \mathrm{HT}-\mathrm{ER} \alpha)$ and C-terminal (ER $\alpha-N l u c, E R \alpha-H T)$ fusion between Nluc and HT with ER $\alpha$ were constructed for testing using the BRET-based dimerization assay. The schematic diagrams are depicted in Figure 1. The vectors had the ampicillin resistance gene, and thus colonies generated on LB plates containing ampicillin were cultured to extract plasmid DNA, which was analyzed for the ER $\alpha$ band by agarose gel separation using Sgfl and PmeI or EcoICRI restriction enzymes. Therefore, it was confirmed that the fusion of Nluc and HT at the N- or the C-terminal of $\mathrm{ER} \alpha$ was in agreement with the prediction (Figure 2). 


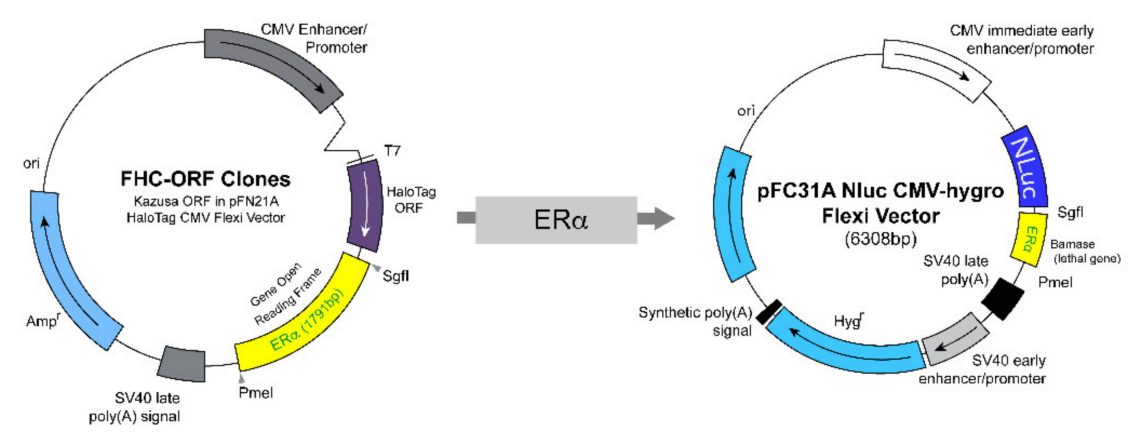

(a)

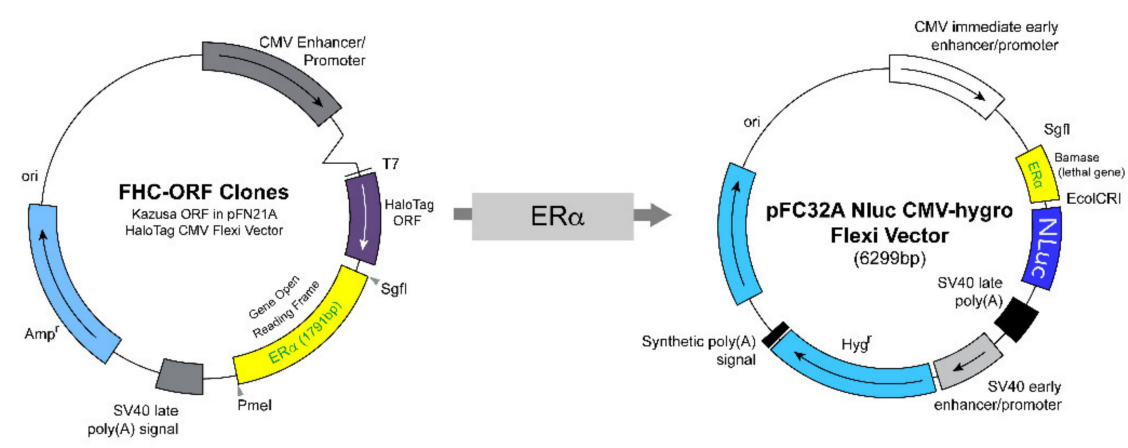

(b)

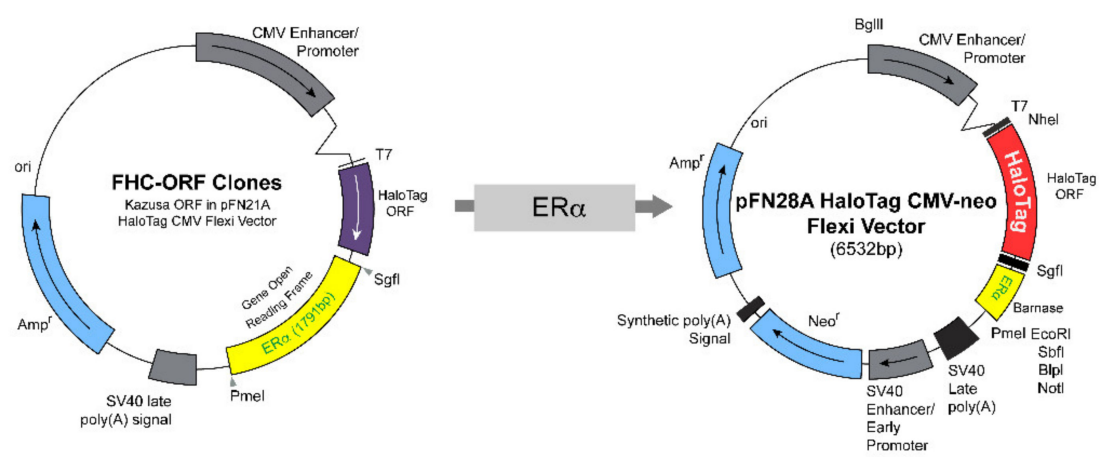

(c)

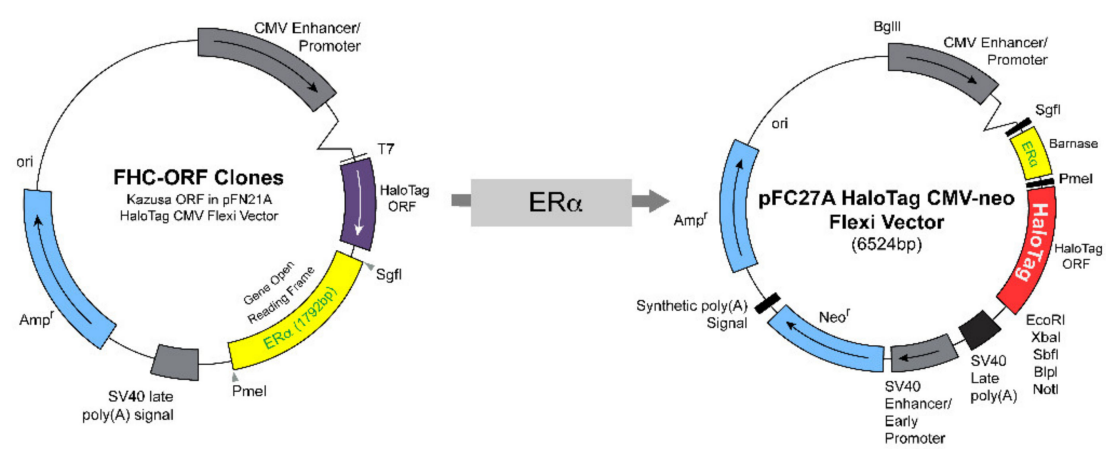

(d)

Figure 1. A description of estrogen receptor-alpha (ER $\alpha)$ combined with NanoLuc luciferase (Nluc) and HaloTag (HT). From the top: (a) Nluc vector combined at N-terminal of ER $\alpha$ (Nluc-ER $\alpha)$, (b) Nluc vector combined at C-terminal of $\mathrm{ER} \alpha(\mathrm{ER} \alpha-\mathrm{Nluc}),(\mathbf{c}) \mathrm{HT}$ vector combined at N-terminal of ER $\alpha(\mathrm{HT}-\mathrm{ER} \alpha)$, (d) HT vector combined at C-terminal of ER $\alpha$ $(\mathrm{ER} \alpha-\mathrm{HT})$. 


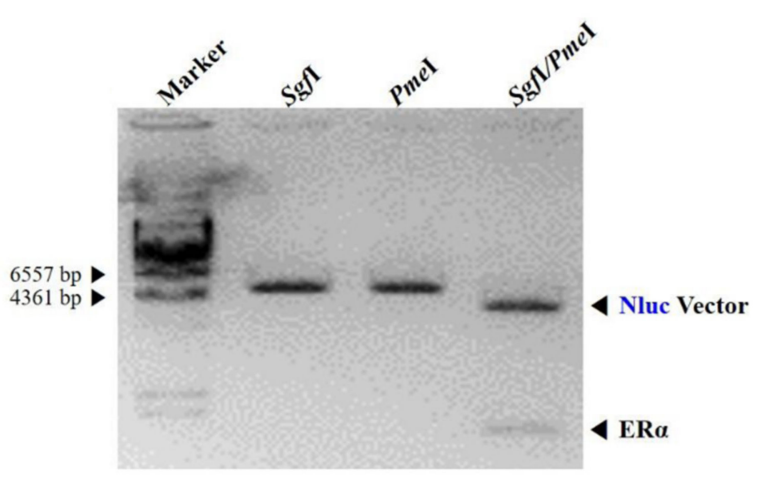

(a)

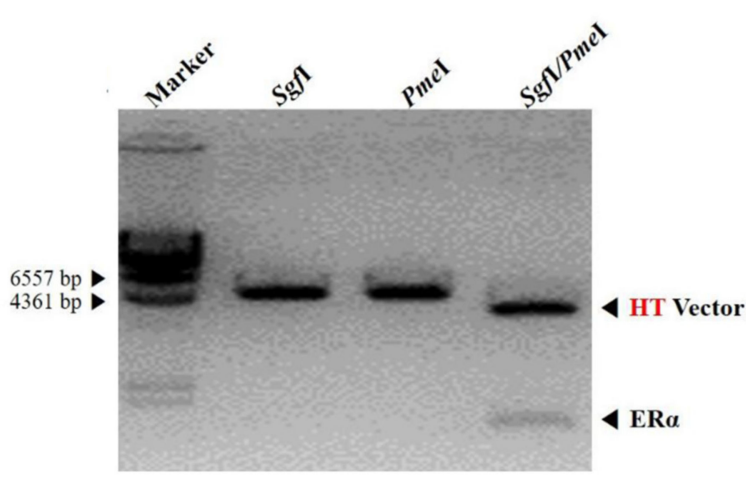

(c)

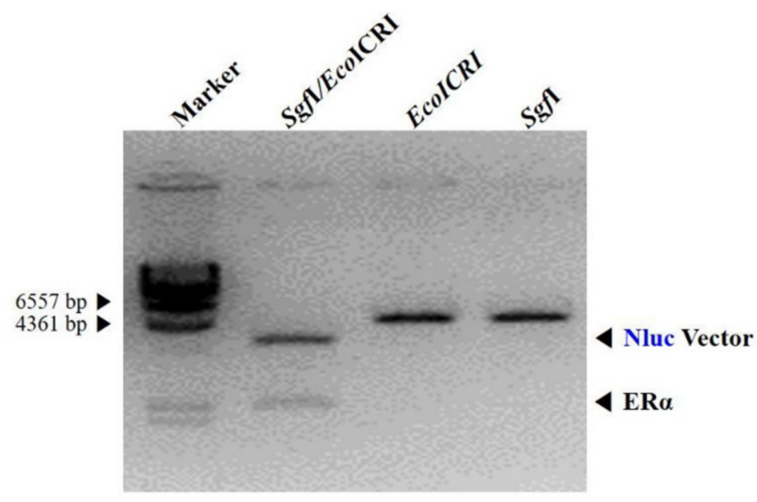

(b)

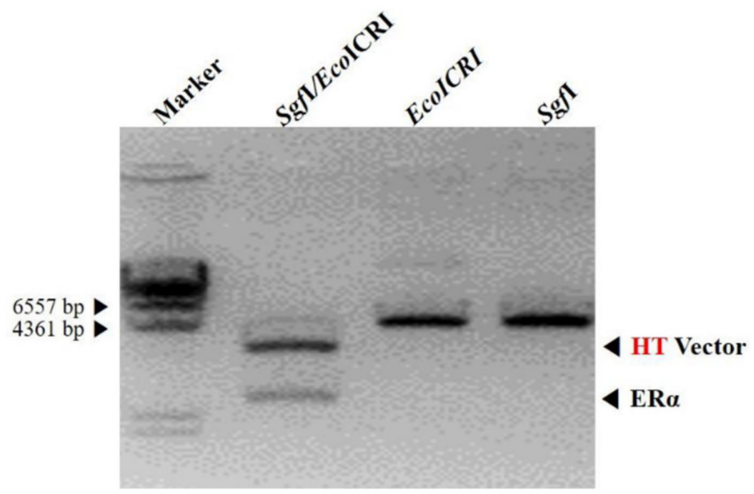

(d)

Figure 2. Estrogen receptor-alpha $(\mathrm{ER} \alpha)$ fused with NanoLuc luciferase (Nluc) and HaloTag (HT) vectors and analyzed by agarose gel electrophoresis. (a) Nluc-ER $\alpha$ : marker, single restriction-enzyme digestion by Sgfl, single restriction-

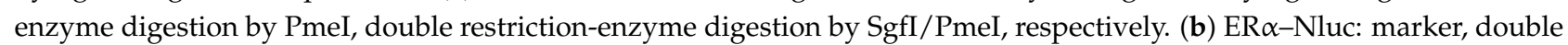
restriction-enzyme digestion by SgfI/EcoICRI, single restriction-enzyme digestion by EcoICRI, single restriction-enzyme digestion by SgfI, respectively. (c) HT-ER $\alpha$ : marker, single restriction-enzyme digestion by SgfI, single restriction-enzyme digestion by PmeI, double restriction-enzyme digestion by SgfI, respectively. (d) ER $\alpha-\mathrm{HT}$ : marker, double restrictionenzyme digestion by SgfI/EcoICRI, single restriction-enzyme digestion by EcoICRI, single restriction-enzyme digestion by SgfI, respectively.

\subsection{Bioluminescence Resonance Energy Transfer Signal by Transient Transfection}

To determine the optimized condition for the BRET signal, the combination ratio and the positions of Nluc (as the donor) and HT (as the acceptor) at the N- or the C-terminal of ER $\alpha$ were confirmed. The BRET signal assay was conducted by treating co-transfected HEK293 cells with $10^{-9} \mathrm{M}$ E2 to select the condition of highest fold induction. First, the four types of vector combinations of ER $\alpha$ fused with Nluc and HT were co-transfected into HEK293 cells in the ratios 1:1, 1:10, 1:100, and 1:1000, respectively. Among the combination position of Nluc and HT with ER $\alpha$, the combination of Nluc and HT fused at the N-terminal of ER $\alpha$ showed significantly increased fold induction compared to other vector combination position $(p<0.001)$ (Figure 3). 


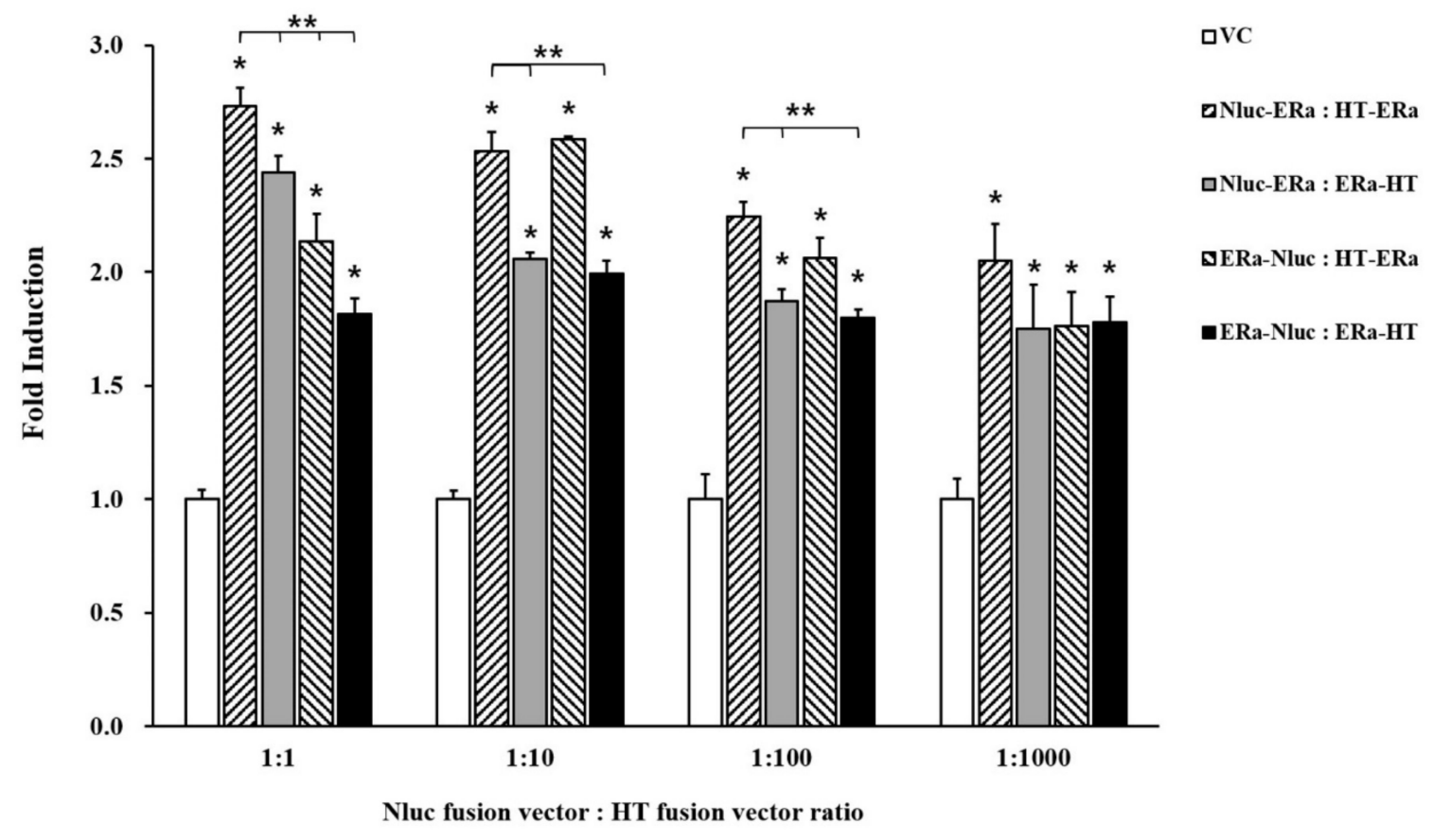

Figure 3. Bioluminescence resonance energy transfer (BRET) signal of the vector combination by transient transfection. BRET signal determined using $10^{-9} \mathrm{M} \mathrm{E} 2$. All data results are expressed as means $\pm \mathrm{SD}(n=3) .{ }^{*} \mathrm{VC} /$ vector combination ratio group $(p<0.001){ }^{* *}$ Nluc-ER $\alpha: H T-E R \alpha /$ other vector combination position group $(p<0.001)$.

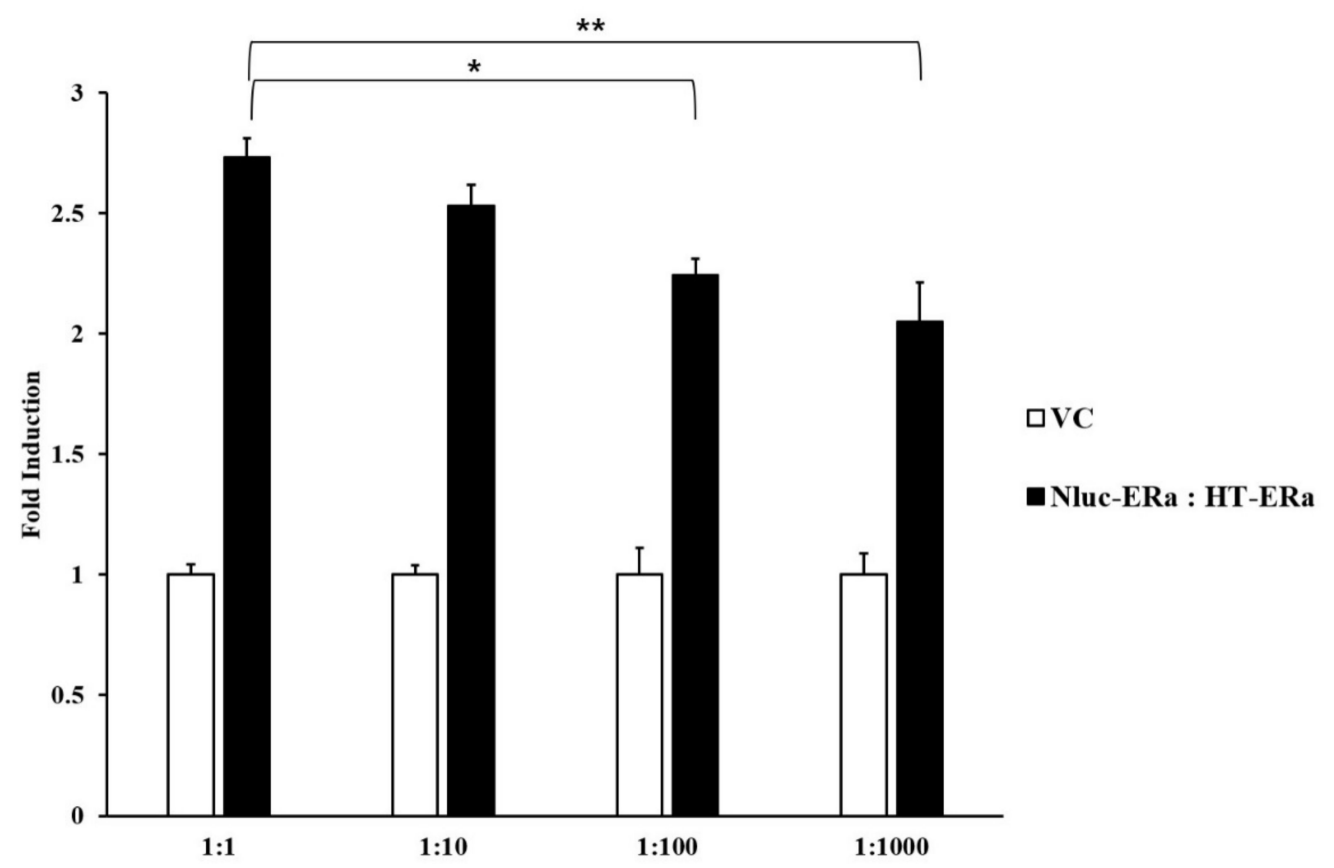

Figure 4. Bioluminescence resonance energy transfer (BRET) signal of the combination 1:1 ratio vector by transient transfection. BRET signal was determined using 10-9 M E2. All data are expressed as means $\pm \mathrm{SD}(\mathrm{n}=3)$. ${ }^{*} 1: 1$ ratio vector of Nluc-ER $\alpha: H T-E R \alpha / 1: 100$ ratio vector of Nluc-ER $\alpha: H T-E R \alpha(p<0.05){ }^{* *}$ 1:1 ratio vector of Nluc-ER $\alpha: H T-E R \alpha / 1: 1000$ ratio vector of Nluc-ER $\alpha: H T-E R \alpha(p<0.001)$.

Next, the ratios 1:1, 1:10, 1:100, and 1:000, respectively, were compared to determine the optimal ratio of Nluc and HT fused at the N-terminal of ER $\alpha$ on transient transfection 
into HEK293 cells (Figure 4). The 1:1 ratio was significantly different compared to 1:1000 $(p<0.05)$ and 1:100 $(p<0.001)$, respectively. These results suggested that the optimal combination ratio and position for Nluc and HT vectors to use in the BRET-based ER $\alpha$ dimerization assay were $1: 1$ and the N-terminal of ER $\alpha$.

\subsection{Bioluminescence Resonance Energy Transfer-Based Estrogen Receptor-Alpha Dimerization Assay}

Based on the result of optimal combination by transient transfection into HEK293 cells, Nluc and HT fused at the N-terminal of ER $\alpha$ in the ratio 1:1, the feasibility of the application of the BRET technique for ER $\alpha$ dimerization assay was confirmed through the BRET signal. he BRET-based ER $\alpha$ dimerization assay was tested using three chemicals, including E2 and $17 \alpha$-estradiol as positive chemicals that bind to ER $\alpha$ and corticosterone as a negative chemical that does not bind to ER $\alpha$. Those chemicals are recommended by the Interagency Coordinating Committee on the Validation of Alternative Test Methods [23] and OECD TG 493 [15]. HEK293 cells were treated with the test chemicals serially diluted to final concentrations from $10^{-7}$ to $10^{-12} \mathrm{M}$ (for E2) and from $10^{-6}$ to $10^{-11} \mathrm{M}$ (for $17 \alpha$-estradiol and corticosterone, respectively). Compared with the VC, the BRET signal for E2 was approximately 2.7 times higher at $10^{-9} \mathrm{M}$ (Figure 5A), and $17 \alpha$-estradiol was approximate 2.7 times higher at $10^{-8} \mathrm{M}$, respectively (Figure $5 \mathrm{~B}$ ). These chemicals showed a dose-dependent sigmoidal curve response for ER $\alpha$. Therefore, E2 and $17 \alpha$-estradiol were suggested as positive chemicals for ER $\alpha$. However, corticosterone showed a comparable response to the VC (Figure 5C), which suggests that it is a negative chemical for ER $\alpha$.

In addition, the BRET-based ER $\alpha$ dimerization assay was conducted for diethylhexyl phthalate, bisphenol A, and 4-nonylphenol, the representative chemicals known as estrogenic endocrine-disrupting chemicals. Compared with the VC, the BRET signals for diethylhexyl phthalate, bisphenol A, and 4-nonylphenol showed a dose-dependent sigmoidal curve for ER $\alpha$. Among them, diethylhexyl phthalate and 4-nonylphenol showed approximately 2.3 times higher induction fold (Figure 5D,F), while bisphenol A was approximately 5.7 times higher at $10^{-5} \mathrm{M}$ (Figure $5 \mathrm{E}$ ). These results suggested the possibility that previously known estrogenic chemicals could also show endocrine-disrupting activity in the form of dimerization activity compared to E2.

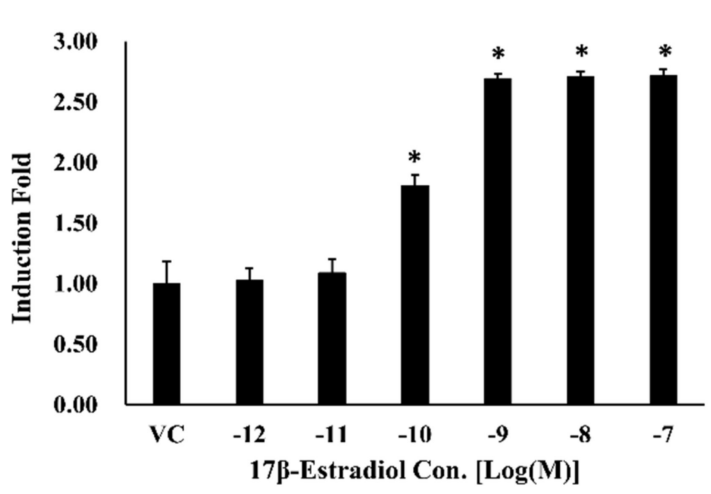

(a)

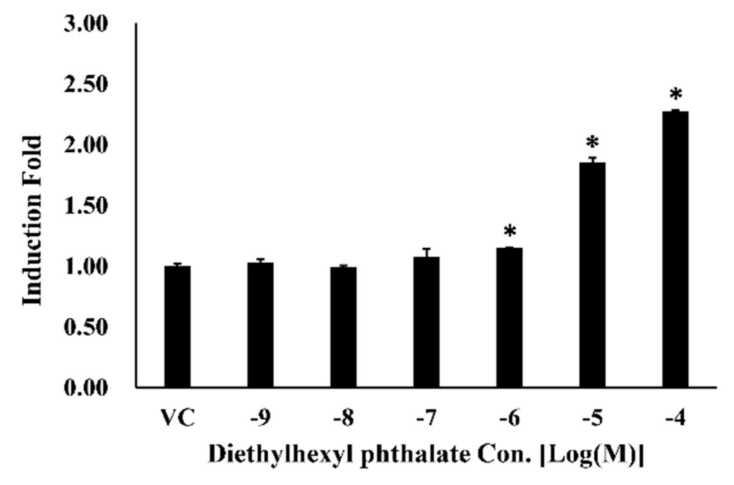

(d)

Figure 5. Cont. 


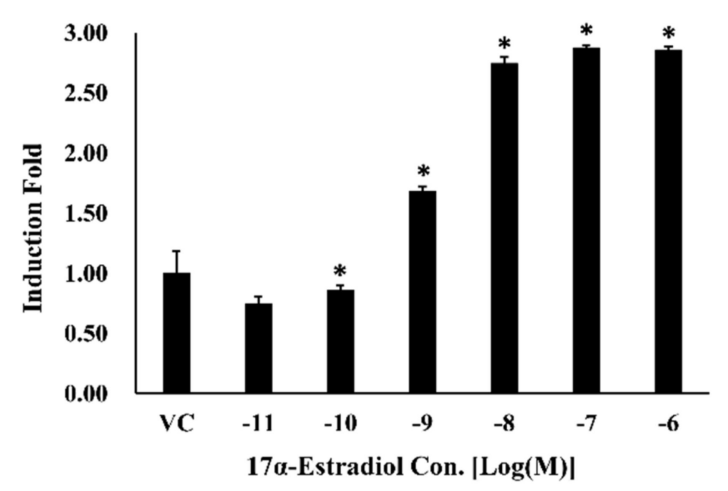

(b)

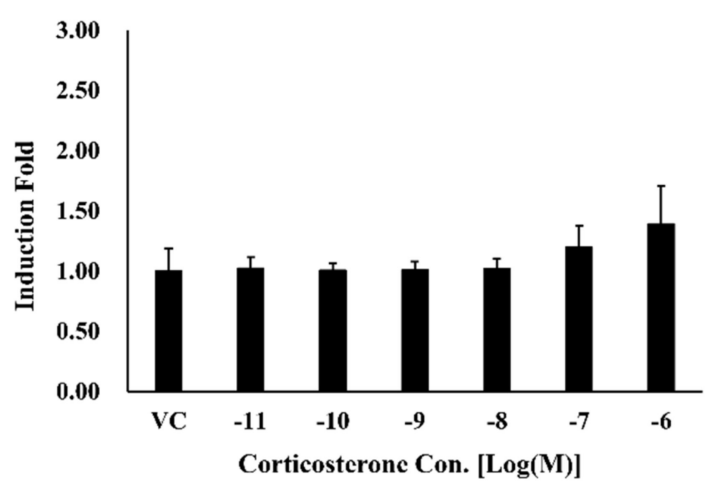

(c)

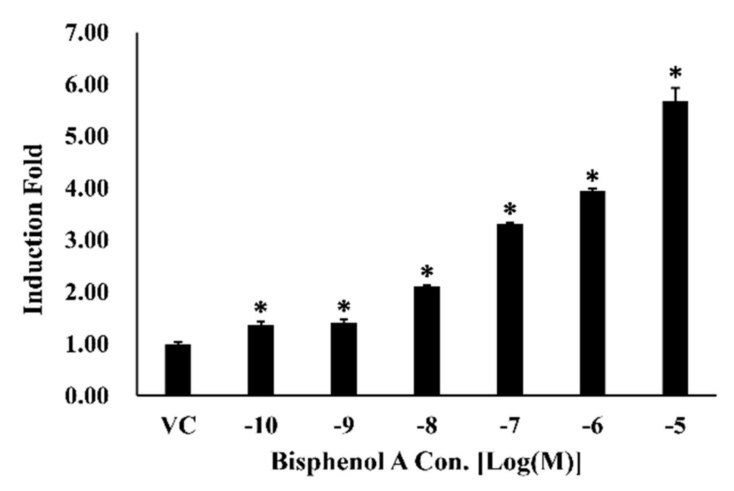

(e)

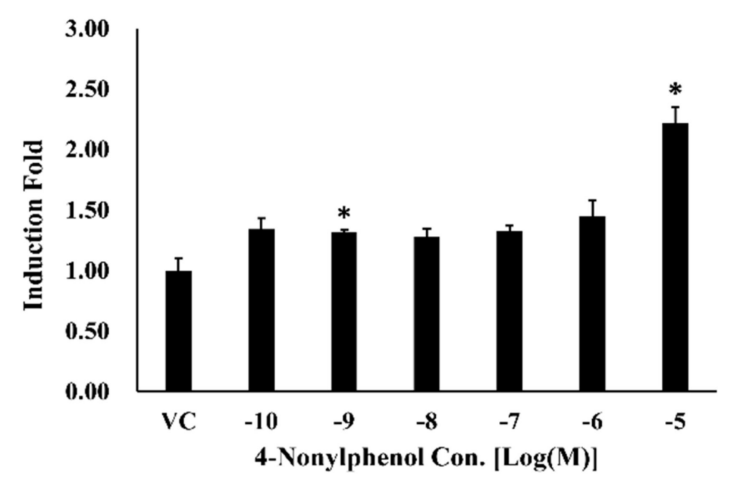

(f)

Figure 5. Bioluminescence resonance energy transfer (BRET) signal induced by treating HEK293 cells with (a) $10^{-7}$ to $10^{-12} \mathrm{M} \mathrm{E2}$, (b) $10^{-6}$ to $10^{-11} \mathrm{M} 17 \alpha$-estradiol, (c) $10^{-6}$ to $10^{-11} \mathrm{M}$ corticosterone, (d) $10^{-4}$ to $10^{-9} \mathrm{M}$ diethylhexyl phthalate, (e) $10^{-5}$ to $10^{-10} \mathrm{M}$ bisphenol A, (f) $10^{-5}$ to $10^{-10} \mathrm{M}$ 4-nonylphenol. All data are expressed as means $\pm \operatorname{SD}(n=3)$. ${ }^{*} 1: 1$ ratio vector of Nluc-ER $\alpha: H T-E R \alpha / 1: 100$ ratio vector of Nluc-ER $\alpha: H T-E R \alpha(p<0.05)$.

\section{Discussion}

EDCs may alter the endocrine system in humans and animals by interfering, mimicking, and blocking production, function, and metabolism of hormones [24]. EDCs can be found in food, packaging materials, cosmetics, consumer products, and many other products. Exposure to EDCs can cause metabolic diseases such as carbohydrate, protein, and lipid metabolic disorders, homeostasis dysfunction, hormone imbalance, and hormonerelated cancers $[25,26]$. Therefore, the development of appropriate tests and assessment methods for EDCs is necessary.

EDCs exert adverse effects on the endocrine system, and some EDCs interact with hormone signaling in cells via nuclear hormone receptors, including ERs, androgen receptors, progesterone receptors, thyroid hormone receptors, and retinoid receptors [4,27]. Among them, estrogenic EDCs interfere with the estrogen signaling pathway by interacting with ERs and disrupt the estrogen function in both in vivo and in vitro model systems [28].

Various kinds of in vitro methods for detecting estrogenic EDCs based on the estrogen action were already developed, such as ligand-binding assay, reporter gene assay, transcription assay, and signaling pathway analysis [13]. Among these methods, ligand-binding assays in which the ligand interacts directly with ERs provide a useful detection strategy for estrogenic EDCs [29]. In particular, the radioligand-binding assay in which a radiolabeled ligand binds to the ER $\alpha$ was recommended in the OECD TG 493 [15]. This approach provides outstanding high-throughput chemical screening and testing capability but has spatial and temporal difficulties associated with data acquisition [30]. Alternatively, the BRET assay used in this study overcame some drawbacks of the radioligand- binding assay. 
BRET-based dimerization assay is suitable for ligand-receptor binding assay and immunological assays of monitoring protein-protein interactions because of a large noise ratio and high sensitivity [20,31]. In addition, the BRET assay can confirm the structural change in the receptor upon binding of the ligand [32]. In the case of ER $\alpha$, homodimerization occurs when the ligand binds to the ER $\alpha$ [33], and the distance between both ER $\alpha$ decreases so that a BRET signal can be measured. Hence, we consider that the BRET assay could be used to improve existing methods and applied for detecting estrogenic EDCs.

Firefly luciferase (Fluc; $61 \mathrm{kDa}$, derived from the firefly Photinus pyralis) or renilla luciferase (Rluc; $36 \mathrm{kDa}$, derived from the sea pansy Renilla reniformis) are commonly used donors. However, these donors have limitations of large protein size and low stability [34]. The recently added Nluc (19 kDa), derived from the deep sea shrimp Oplophorus gracilirostris, can improve the performance of the BRET assay because of its smaller protein size compared with that of existing donors [35]. Furthermore, Nluc is more stable and demonstrates a higher luminescence intensity than Fluc and Rluc [36]. Additionally, as a long-wavelength fluorophore, HT is preferred for the BRET assay because it improves the spectral separation from donor luciferase and enables the rapid evaluation of various fluorophores [37]. Therefore, the NanoBRET system uses Nluc and HT to maintain the activity of Nluc and has higher efficiency than the conventional BRET assay [38].

In this study, we demonstrated the development of an ER $\alpha$ dimerization assay based on the NanoBRET system with Nluc and HT. Before using the NanoBRET system with donor Nluc and acceptor HT, a fusion vector containing ER must be established. The two different isoforms of the ER (ER $\alpha$ and $E R \beta)$ both have the estrogen function in humans [39]. $\mathrm{ER} \alpha$ is widely expressed and regulates various physiological functions, whereas $\mathrm{ER} \beta$ is involved in some aspects of mating behavior, regulation of ovulation, and immune responses [40]. In addition, OECD TG 493 describes the binding assay using ER $\alpha$ [15]. In this study, the experiments were performed with an ER $\alpha$ isoform.

We studied transient transfection performed in HEK 293 cells after constructing four different vector combinations of Nluc and HT fused with ER $\alpha$. Then, we identified the optimal combination vectors by measuring the intensity of the BRET signal after treatment of E2, because it is well known that the BRET signal is influenced by the relative distance of the donor and the acceptor within the ER homodimer [41]. In this study, the highest values of fold induction for BRET signal were selected when compared with VC following E2 treatment. As a result, we obtained the increase fold induction when Nluc and HT vectors were fused at the $\mathrm{N}$-terminal of $\mathrm{ER} \alpha$, respectively, and transient transfection into HEK293 cells in a 1:1 ratio. These data suggested that, if Nluc and HT are located at the $\mathrm{N}$-terminal of $\mathrm{ER} \alpha$, the distance between the two ER $\alpha$ s in the homodimer would be more minimized than other combinations, increasing the efficiency of energy transferred from Nluc to HT, which, in turn, would enhance the BRET signal. Therefore, by establishing the optimal condition for the ER $\alpha$ dimerization assay based on the NanoBRET system, it enhances the performance of the dimerization assay for detecting estrogenic EDCs using the in vitro model.

After establishing the optimal combination vector, we investigated whether using the $\mathrm{ER} \alpha$ dimerization assay based on the NanoBRET system is better than using a conventional binding assay. We tested the dimerization ability of chemicals with ER $\alpha$ using the NanoBRET system by selecting the chemicals E2, 17 $\alpha$-estradiol, and corticosterone based on ICCVAM [23] and OECD TG 493 [15]. In this study, E2 and $17 \alpha$-estradiol showed a dose-dependent response for $\operatorname{ER} \alpha$ (Figures $5 \mathrm{~A}$ and $4 \mathrm{~B}$ ), indicating that these are positive chemicals for ER $\alpha$, which is consistent with ICCVAM and OECD TG 493. Besides, E2 and $17 \alpha$-estradiol bound to the ER $\alpha$ to activate estrogen signaling by estrogen responsive elements regulation [28,42]. Accordingly, this finding indicated that these chemicals were bound to ER $\alpha$ to form a homodimer so that the energy of the Nluc donor was transferred to the HT acceptor, which, in turn, emitted fluorescence, enabling measurement of the BRET signal. Contrastingly, corticosterone did not show a dose-dependent response for $\mathrm{ER} \alpha$ (Figure 5C). In other words, energy transfer between Nluc and HT by corticosterone 
did not occur, which confirmed that corticosterone did not induce the formation of ER $\alpha$ homodimers. Therefore, corticosterone is classified as a negative chemical for ER $\alpha$. Moreover, although this chemical is classified as a presumed negative chemical for ER $\alpha$ in the ICCVAM, the results of this study showed definitively that negative chemicals could be confirmed through the BRET signal, suggesting that the NanoBRET system is more accurate compared with conventional binding assays. Consequently, Nluc and HT can replace the radioligand in the conventional binding assay for $\mathrm{ER} \alpha$ that is used to evaluate estrogenic EDCs. Moreover, the novel ER $\alpha$ dimerization assay using the NanoBRET system is able to detect estrogenic EDCs more sensitively and precisely than existing binding assays.

\section{Conclusions}

We established a novel dimerization assay using the NanoBRET system to detect estrogenic EDC-mediated dimerization of ER $\alpha$. In order to optimize the NanoBRET system, Nluc and HT were selected with a ratio 1:1 at the N-terminal of Er $\alpha$ after vector construction. The combination of Nluc and HT has the advantage that higher efficiency can be maintained relative to other conventional combinations. To measure the BRET signal for ER $\alpha$, the treating substances were selected with reference to OECD TG 493 and ICCVAM. The results were consistent with both references that conducted the dimerization assay for ER $\alpha$ when using the established NanoBRET system. Moreover, the NanoBRET system can provide accurate substance information. Our results suggest that estrogenic EDCs affecting the estrogen function in vivo can be detected and evaluated by the NanoBRET system more efficiently and accurately. Therefore, this dimerization assay could be used to determine the properties of estrogenic EDCs in foods or substances present in the surrounding environment. Further research is needed to validate our study showing that the BRET signal was confirmed from other EDCs to increase accuracy for the ER $\alpha$ dimerization assay based on the NanoBRET system.

Author Contributions: Conceptualization, Y.P., S.-H.L. and K.S.K.; Data curation, H.M.K., H.S. and S.-H.L.; Formal analysis, H.-S.L. and K.S.K.; Investigation, H.M.K., H.S. and S.-H.L.; Methodology, H.-S.L., Y.P. and K.S.K.; Project administration, Y.P., S.-H.L. and K.S.K.; Resources, Y.P. and K.S.K.; Supervision, S.-H.L. and K.S.K.; Validation, H.-S.L. and Y.P.; Visualization, H.M.K., H.S. and S.-H.L.; Writing-original draft, H.M.K., H.S. and S.-H.L. All authors have read and agreed to the published version of the manuscript.

Funding: This research was supported by grants (18163MFDS109, 2020R1A2C1102451) from Ministry of Food and Drug Safety in 2019 and the National Research Foundation of Korea (NRF) respectively.

Institutional Review Board Statement: Not applicable.

Informed Consent Statement: Not applicable.

Data Availability Statement: The data that support the findings of this study are available from the corresponding author upon reasonable request.

Conflicts of Interest: The authors declare no conflict of interest.

\section{References}

1. Schug, T.T.; Janesick, A.; Blumberg, B.; Heindel, J.J. Endocrine disrupting chemicals and disease susceptibility. J. Steroid Biochem. Mol. Biol. 2011, 127, 204-215. [CrossRef]

2. Cotterill, J.V.; Palazzolo, L.; Ridgway, C.; Price, N.; Rorije, E.; Moretto, A.; Peijnenburg, A.; Eberini, I. Predicting estrogen receptor binding of chemicals using a suite of in silico methods-Complementary approaches of (Q)SAR, molecular docking and molecular dynamics. Toxicol. Appl. Pharmacol. 2019, 378, 114630. [CrossRef]

3. Welshons, W.V.; Thayer, K.A.; Judy, B.M.; Taylor, J.A.; Curran, E.M.; vom Saal, F.S. Large effects from small exposures. I. Mechanisms for endocrine-disrupting chemicals with estrogenic activity. Environ. Health Perspect. 2003, 111, 994-1006. [CrossRef] [PubMed]

4. Diamanti-Kandarakis, E.; Bourguignon, J.P.; Giudice, L.C.; Hauser, R.; Prins, G.S.; Soto, A.M.; Zoeller, R.T.; Gore, A.C. Endocrinedisrupting chemicals: An Endocrine Society scientific statement. Endocr. Rev. 2009, 30, 293-342. [CrossRef] [PubMed]

5. Deng, Z.H.; Li, N.; Jiang, H.L.; Lin, J.M.; Zhao, R.S. Pretreatment techniques and analytical methods for phenolic endocrine disrupting chemicals in food and environmental samples. TrAC Trends Anal. Chem. 2019, 119, 115592. [CrossRef] 
6. Locatelli, M.; Sciascia, F.; Cifelli, R.; Malatesta, L.; Bruni, P.; Croce, F. Analytical methods for the endocrine disruptor compounds determination in environmental water samples. J. Chromatogr. A 2016, 1434, 1-18. [CrossRef]

7. Mezcua, M.; Martínez-Uroz, M.A.; Gómez-Ramos, M.M.; Gómez, M.J.; Navas, J.M.; Fernández-Alba, A.R. Analysis of synthetic endocrine-disrupting chemicals in food: A review. Talanta 2012, 100, 90-106. [CrossRef]

8. Eng, D.S.; Lee, J.M.; Gebremariam, A.; Meeker, J.D.; Peterson, K.; Padmanabhan, V. Bisphenol A and chronic disease risk factors in US children. Pediatrics 2013, 132, e637-e645. [CrossRef] [PubMed]

9. Rubin, B.S.; Paranjpe, M.; DaFonte, T.; Schaeberle, C.; Soto, A.M.; Obin, M.; Greenberg, A.S. Perinatal BPA exposure alters body weight and composition in a dose specific and sex specific manner: The addition of peripubertal exposure exacerbates adverse effects in female mice. Reprod. Toxicol. 2017, 68, 130-144. [CrossRef]

10. Colborn, T.; Vom Saal, F.S.; Soto, A.M. Developmental effects of endocrine-disrupting chemicals in wildlife and humans. Environ. Health Perspect. 1993, 101, 378-384. [CrossRef] [PubMed]

11. Li, Q.; Lam, M.H.W.; Wu, R.S.S.; Jiang, B. Rapid magnetic-mediated solid-phase extraction and pre-concentration of selected endocrine disrupting chemicals in natural waters by poly(divinylbenzene-co-methacrylic acid) coated $\mathrm{Fe}_{3} \mathrm{O}_{4}$ core-shell magnetite microspheres for their liquid chromatography-ta. J. Chromatogr. A 2010, 1217, 1219-1226. [CrossRef]

12. Diel, P.; Smolnikar, K.; Michna, H. In vitro test systems for the evaluation of the estrogenic activity of natural products. Planta Med. 1999, 65, 197-203. [CrossRef]

13. Kiyama, R.; Wada-Kiyama, Y. Estrogenic endocrine disruptors: Molecular mechanisms of action. Environ. Int. 2015, 83, 11-40. [CrossRef]

14. Li, Z.; Zhang, H.; Gibson, M.; Li, J. An evaluation on combination effects of phenolic endocrine disruptors by estrogen receptor binding assay. Toxicol. Vitr. 2012, 26, 769-774. [CrossRef]

15. OECD. OECD Test No. 493: Performance-Based Test Guideline for Human Recombinant Estrogen Receptor (hrER) In vitro Assays to Detect Chemicals with ER Binding Affinity. In OECD Guidelines for the Testing of Chemicals, Section 4; OECD Publishing: Paris, France, 2015; ISBN 9789264242623.

16. De Jong, L.A.A.; Uges, D.R.A.; Franke, J.P.; Bischoff, R. Receptor-ligand binding assays: Technologies and applications. J. Chromatogr. B Anal. Technol. Biomed. Life Sci. 2005, 829, 1-25. [CrossRef] [PubMed]

17. Chu, Y.; Han, T.; Deng, A.; Li, L.; Zhu, J.J. Resonance energy transfer in electrochemiluminescent and photoelectrochemical bioanalysis. TrAC Trends Anal. Chem. 2020, 123, 115745. [CrossRef]

18. Wang, C.; Bian, W.; Xia, C.; Zhang, T.; Guillemot, F.; Jing, N. Visualization of bHLH transcription factor interactions in living mammalian cell nuclei and developing chicken neural tube by FRET. Cell Res. 2006, 16, 585-598. [CrossRef]

19. Piston, D.W.; Kremers, G.J. Fluorescent protein FRET: The good, the bad and the ugly. Trends Biochem. Sci. 2007, 32, 407-414. [CrossRef]

20. Michelini, E.; Mirasoli, M.; Karp, M.; Virta, M.; Roda, A. Development of a bioluminescene resonance energy-transfer assay for estrogen-like compound in vivo monitoring. Anal. Chem. 2005, 76, 7069-7076. [CrossRef]

21. Xu, Y.; Piston, D.W.; Johnson, C.H. A bioluminescence resonance energy transfer (BRET) system: Application to interacting circadian clock proteins. Proc. Natl. Acad. Sci. USA 1999, 96, 151-156. [CrossRef] [PubMed]

22. Boute, N.; Jockers, R.; Issad, T. The use of resonance energy transfer in high-throughput screening: BRET versus FRET. Trends Pharmacol. Sci. 2002, 23, 351-354. [CrossRef]

23. ICCVAM. ICCVAM Evaluation of In Vitro Test Methods for Detecting Potential Endocrine Disruptors: Estrogen Receptor and Androgen Receptor Binding and Transcriptional Activation Assays; No. 03-4503; NIH Publication: Bethesda, MD, USA, 2003.

24. Yang, F.W.; Li, Y.X.; Ren, F.Z.; Luo, J.; Pang, G.F. Assessment of the endocrine-disrupting effects of organophosphorus pesticide triazophos and its metabolites on endocrine hormones biosynthesis, transport and receptor binding in silico. Food Chem. Toxicol. 2019, 133, 110759. [CrossRef]

25. Park, M.-A.; Hwang, K.-A.; Choi, K.-C. Diverse animal models to examine potential role(s) and mechanism of endocrine disrupting chemicals on the tumor progression and prevention: Do they have tumorigenic or anti-tumorigenic property? Lab. Anim. Res. 2011, 27, 265. [CrossRef] [PubMed]

26. Akash, M.S.H.; Sabir, S.; Rehman, K. Bisphenol A-induced metabolic disorders: From exposure to mechanism of action. Environ. Toxicol. Pharmacol. 2020, 77, 103373. [CrossRef]

27. Wang, C.; Yang, L.; Wang, S.; Zhang, Z.; Yu, Y.; Wang, M.; Cromie, M.; Gao, W.; Wang, S.-L. The classic EDCs, phthalate esters and organochlorines, in relation to abnormal sperm quality: A systematic review with meta-analysis. Sci. Rep. 2016, 6, 19982. [CrossRef]

28. Li, Y.; Luh, C.J.; Burns, K.A.; Arao, Y.; Jiang, Z.; Teng, C.T.; Tice, R.R.; Korach, K.S. Endocrine-disrupting chemicals (EDCs): In vitro mechanism of estrogenic activation and differential effects on ER target genes. Environ. Health Perspect. 2013, 121, 459-466. [CrossRef]

29. Shanle, E.K.; Xu, W. Endocrine disrupting chemicals targeting estrogen receptor signaling: Identification and mechanisms of action. Chem. Res. Toxicol. 2011, 24, 6-19. [CrossRef]

30. Zeilinger, M.; Pichler, F.; Nics, L.; Wadsak, W.; Spreitzer, H.; Hacker, M.; Mitterhauser, M. New approaches for the reliable in vitro assessment of binding affinity based on high-resolution real-time data acquisition of radioligand-receptor binding kinetics. EJNMMI Res. 2017, 7, 22. [CrossRef] 
31. Tang, Y.; Parag-Sharma, K.; Amelio, A.L.; Cao, Y. A Bioluminescence Resonance Energy Transfer-Based Approach for Determining Antibody-Receptor Occupancy In vivo. Iscience 2019, 15, 439-451. [CrossRef] [PubMed]

32. Issad, T.; Boute, N.; Pernet, K. A homogenous assay to monitor the activity of the insulin receptor using Bioluminescence Resonance Energy Transfer. Biochem. Pharmacol. 2002, 64, 813-817. [CrossRef]

33. Hall, J.M.; Couse, J.F.; Korach, K.S. The Multifaceted Mechanisms of Estradiol and Estrogen Receptor Signaling. J. Biol. Chem. 2001, 276, 36869-36872. [CrossRef]

34. Hall, M.P.; Unch, J.; Binkowski, B.F.; Valley, M.P.; Butler, B.L.; Wood, M.G.; Otto, P.; Zimmerman, K.; Vidugiris, G.; MacHleidt, T.; et al. Engineered luciferase reporter from a deep sea shrimp utilizing a novel imidazopyrazinone substrate. ACS Chem. Biol. 2012, 7, 1848-1857. [CrossRef]

35. Dale, N.C.; Johnstone, E.K.M.; White, C.W.; Pfleger, K.D.G. NanoBRET: The bright future of proximity-based assays. Front. Bioeng. Biotechnol. 2019, 7, 56. [CrossRef] [PubMed]

36. Stoddart, L.A.; Kilpatrick, L.E.; Hill, S.J. NanoBRET Approaches to Study Ligand Binding to GPCRs and RTKs. Trends Pharmacol. Sci. 2018, 39, 136-147. [CrossRef]

37. Machleidt, T.; Woodroofe, C.C.; Schwinn, M.K.; Méndez, J.; Robers, M.B.; Zimmerman, K.; Otto, P.; Daniels, D.L.; Kirkland, T.A.; Wood, K.V. NanoBRET-A Novel BRET Platform for the Analysis of Protein-Protein Interactions. ACS Chem. Biol. 2015, 10, 1797-1804. [CrossRef]

38. Nath, N.; Flemming, R.; Godat, B.; Urh, M. Development of NanoLuc bridging immunoassay for detection of anti-drug antibodies. J. Immunol. Methods 2017, 450, 17-26. [CrossRef]

39. Soltysik, K.; Czekaj, P. Membrane estrogen receptors-Is it an alternative way of estrogen action? J. Physiol. Pharmacol. 2013, 64, 129-142.

40. Hall, J.M.; Mcdonnell, D.P. Coregulators in Nuclear Estrogen Receptor Action. Mol. Interv. 2005, 5, 343-357. [CrossRef]

41. Powell, E.; Xu, W. Intermolecular interactions identify ligand-selective activity of estrogen receptor $\alpha / \beta$ dimers. Proc. Natl. Acad. Sci. USA 2008, 105, 19012-19017. [CrossRef]

42. Santos, R.S.; De Fatima, L.A.; Frank, A.P.; Carneiro, E.M.; Clegg, D.J. The effects of 17 alpha-estradiol to inhibit inflammation in vitro. Biol. Sex. Differ. 2017, 8, 30. [CrossRef] 